\title{
Geotechnical Materials for Floor Covering: Dioritic Noritic "Granite" Plates Structural Behavior
}

\author{
Sérgio T. F. Moreiras, Antenor B. Paraguassú, and Rogério P. Ribeiro
}

\begin{abstract}
Polished finishing granites have great acceptance in non-adherent covering systems because of the slabs' shape design, color variety and the high level of mechanical properties and durability. The Brazilian practice for natural stone design applies only the bending tensile strength test results and other important characteristics are not taken in account. Thus, this study evaluated the mechanical properties of the stone for non-adherent paving uses as structural slab and pedestal paving system. The properties assessed for the dioritic noritic Black São Gabriel were the stress versus deformation diagram, the Young modulus (E) and the Poisson's ratio $(\mu)$. The tests were running in compression and in bending modes. The results showed a good correlation between the five Young modulus (E) obtained.
\end{abstract}

Index Terms-Granite' slab, structural behavior, non adherent covering system, Young's modulus (E).

\section{INTRODUCTION}

Brazil's productivity in building industry is small when compared with other countries. The Brazilian workers' average productivity in U.S. dollars is five to seven times lower than that of European and American workers and the average delivery time of the construction works is two to three times higher [1].

An example of this low productivity can be observed in the Brazilian masonry, where about $96 \%$ of the works are carried out using ceramic or concrete bricks. Another fact is that over $70 \%$ of slabs used in mid-sized houses in Brazil are carried out using a mixed system of ceramic blocks, pre-cast concrete beams, concrete and mortar, and this does not take into account the materials used in floor coverings [1].

Data released by the federal government of Brazil shows that the actual housing deficit is of 5.546 million homes, $83.5 \%$ in urban areas.

On the other hand, in last year Brazil produced 3.9 million tons of granite blocks. Of this total, approximately 65 million square meters of plates were absorbed by the domestic market, used mainly for covering buildings [2]. Therefore, based on the existing housing demand in Brazil, on the physical and mechanical properties of granites and on the low productivity of the methods used to execute slabs, this work addresses the feasibility of using granite plates as slabs in buildings. Value is added to granite plates with this

Manuscript received May 14, 2014; revised July 21, 2014. This work was supported by the Brazilian Agency for Research and Development - CNPq.

S. T. F. Moreiras is with the Technology Department, State University of Maringá, Umuarama, PR 87506-370 Brazil (e-mail: strajano@gmail.com).

A. B. Paraguassú and R. P. Ribeiro are with the Engineering Geotechnical Department, University of São Paulo, São Carlos, SP 13566-590 Brazil (e-mail: nonus@sc.usp.br, rogerpin@yahoo.com). implementation, which in addition to its coating function it also has structural slab functions. So, this paper provides a methodology for the structural properties applied in non-adherent floor covering systems.

\section{NON AdHERENT FLOOR COVERING SySTEMS}

The both proposed assembling systems for granite plates, in this paper, does not use mortar. They are supports by the edges of the slabs, so the bottom part of the plate is not fixed in any part of the building. For these reason, tensile efforts acts at the bottom side of the plates.

\section{A. Structural Slab System}

The granite slabs are supported by the edges on a frame system of concrete beams, which should be designed to support the weight of the slabs and other live loads (Fig. 1). The benefits of using these non-adherent systems for floor covering are the lower load levels in the structure of the building, the assemblage facility and the high productivity.

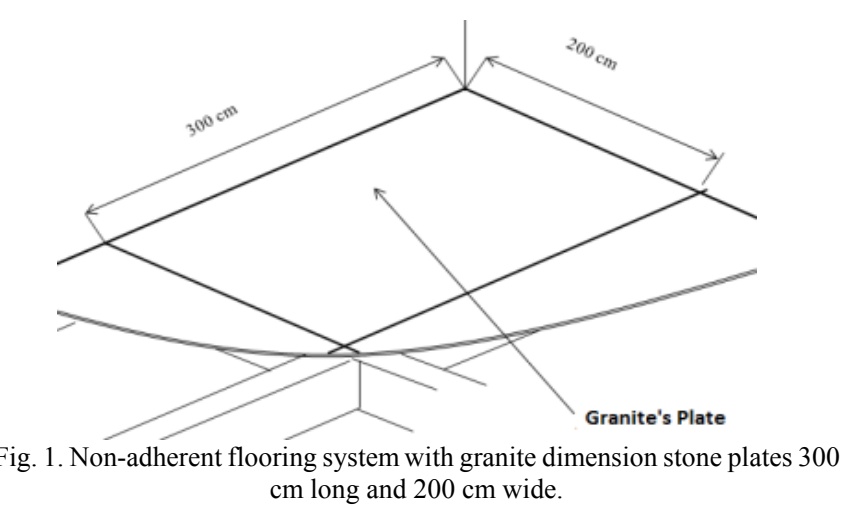

The slabs with dimensions of 200 and $300 \mathrm{~cm}$ and $30 \mathrm{~mm}$ thickness are of approximately $500 \mathrm{~kg}$. To assemble these slabs, they can be hoisted and moved horizontally with a one-ton minimum capacity mechanical hoist. The slabs must be raised before implementing the external masonry.

The assembling of the slabs cannot start before the flatness and the level of the superior face of the concrete beams are checked. The transition joints between the slabs have to be designed to allow thermal stone deformation and to accommodate the deviations of the length and width of the slabs, which occur during production. The thermal deformation value of the rock obtained in agreement with the directions of European standard is less than $1 \mathrm{~mm} \mathrm{[3].} \mathrm{The}$ allowable tolerance in the length and width of slabs with 200 $\mathrm{cm}$ by $300 \mathrm{~cm}$ is $1.5 \mathrm{~mm}$ more or less [4], [5]. Therefore, to accommodate the dimensional and thermal variations, an joint of $4 \mathrm{~mm}$ in width is specified. 
To protect the stone against driving rain an elastic sealant should be specified. This sealant is supported in a flexible circular string of polyethylene fixed inside the joint, in accordance with the details in Fig. 2.

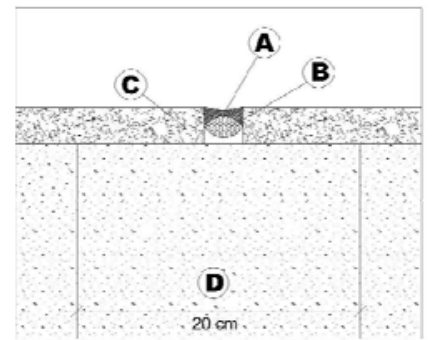

Fig. 2. Details of the non-adherent flooring systems. Where " $A$ " is the elastic joint sealant;" $\mathrm{B}$ " is the flexible circular string of polyethylene; " $\mathrm{C}$ " is granite plate;"D" is the concrete beam $20 \mathrm{~cm}$ wide and $50 \mathrm{~cm}$ high.

\section{B. Pedestal Paving Systems}

The "granite" plates used in the pedestal paving systems are generally $50 \times 50,60 \times 60$ and $70 \times 70 \mathrm{~cm}$ in size. The four corners of the plates are supported on pedestals and suspended above the ground (Fig. 3). The most commonly used materials for manufacturing the supports are polyethylene, polypropylene and PVC. According to BS EN 1339 standard [6] the supports should have minimum base area of $300 \mathrm{~cm}^{2}$ and upper area of $100 \mathrm{~cm}^{2}$.

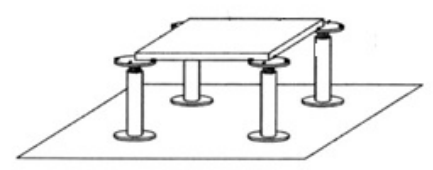

Fig. 3. Pedestal paving systems.

The allowable tolerance of more or less $3 \mathrm{~mm}$ for the thickness [4] can cause performance problems on the floor. Therefore, plates for floor covering in non-adherent systems cannot have thickness variations. To produce slabs with these characteristics, multi-wire looms or diamond grinding wheel equipment can be used, which eliminates the deviations.

\section{MATERIALS AND METHODS}

\section{A. Petrographic Analysis}

The diorite noritic Sao Gabriel Black is a compact structure and coarse grained dark gray rock. The mineralogical composition is $60 \%$ plagioclase (andesine labradorite), $15 \%$ hypersthene, $15 \%$ biotite, $5 \%$ hornblende and $5 \%$ quartz.

\section{B. Instrumented Tensile Bending Test}

Guidelines for the four-point load test are given in the ASTM C 880 standard [7]. Although there is no standard for the three-point flexural tensile strength test, so the directions of [7] were applied, changing only the number and positioning of the upper rod. The instrumentation used to determine the structural behavior and Young's modulus was performed by bolding strain-gages in the longitudinal direction of the center of the top and bottom side of the samples (Fig. 4). Data acquisition was at the loading rate of 4
$\mathrm{MPa} / \mathrm{min}$. The Young's modulus (E) was obtained by dividing the variation of stress by the respective variation strain in the elastic part of the diagram.

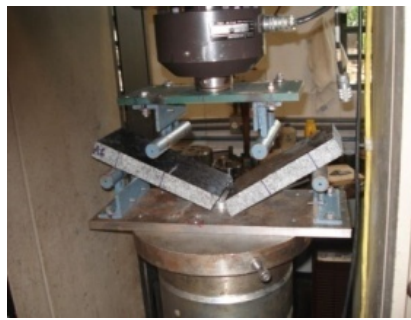

(a) (b)

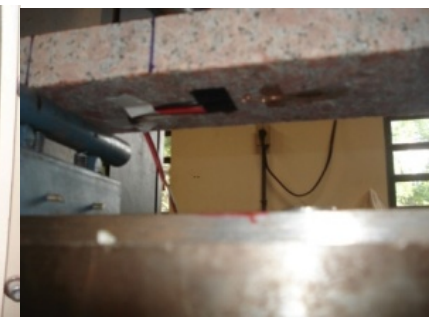

Fig. 4. Four-point load test on plates of $30 \mathrm{~mm}$ thickness. (a) End of test; (b) Detail of the installation of the deformation strain gauge.

For each type of rock, for each type of test ( 3 and 4 points load test), and for each thickness (20 and $30 \mathrm{~mm}$ ) six samples were used to determine the ultimate bending tensile strength in flexion and another six samples were used to determine Young's module in flexion.

\section{Instrumented Uniaxial Compression Test}

To determine the ultimate compression strength, the stress versus longitudinal and lateral strain diagram, the Young's modulus (E) in compression mode and Poisson's ratio $(\mu)$, the guidelines of ASTM D 7012 standard [8] were followed. Six cylindrical specimens (74 $\mathrm{mm}$ in length and $165 \mathrm{~mm}$ in height) were tested. The loading rate was applied so as to cause the specimen a stress increase of 0.5 to $1.0 \mathrm{MPa} / \mathrm{s}$.

Fig. 5 shows the test for determining the axial and circumferential displacements according to load applied. Where " $\mathrm{A}$ " is the sensor for determining the circumferential displacement and " $\mathrm{B}$ " is the sensor for determining the longitudinal displacement (initial reading section of $65 \mathrm{~mm}$ ).

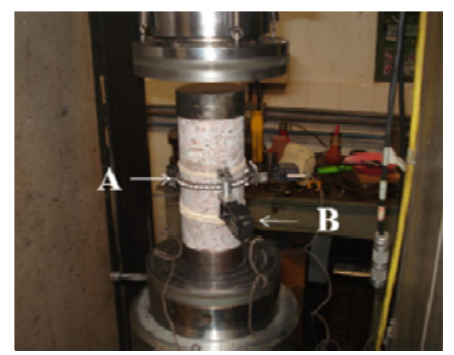

Fig. 5. Test for determining the Young's modulus and Poisson's coefficient compression.

TABLE I: RESUltS OF THE BENDING TENSILE TESTS

\begin{tabular}{cccc}
\hline Test & $\begin{array}{c}\sigma_{f} \\
(\mathrm{MPa})\end{array}$ & $\begin{array}{c}\text { S.D. } \\
(\mathrm{MPa})\end{array}$ & C.V. \\
\hline 4 Points; Th $=30 \mathrm{~mm}$ & 14.45 & 1.33 & 0.092 \\
4 Points; Th $=20 \mathrm{~mm}$ & 18.93 & 1.37 & 0.072 \\
3 Points; Th $=30 \mathrm{~mm}$ & 18.21 & 1.8 & 0.099 \\
3 Points; Th $=20 \mathrm{~mm}$ & 20.68 & 1.45 & 0.070
\end{tabular}

Legend: Th is the thickness, $\sigma_{f}$ is the bending tensile results media, S.D. is the standard deviation and C.V. is the coefficient of variation.

The Poisson's ratio $(\mu)$ was obtained by equation (1):

$$
\mu=-\left[E /\left(\Delta \sigma / \Delta \varepsilon_{d}\right)\right]
$$

where: $\Delta \sigma$ is the stress variation and $\Delta \varepsilon_{d}$ is the diametrical strain variation. 


\section{RESULtS}

The results of the ultimate strength of bending tensile tests are presented Table I. The stress versus strain curves are presented in Fig. 6-Fig. 9. The respective Young modulus in bending mode is presented in Table II.

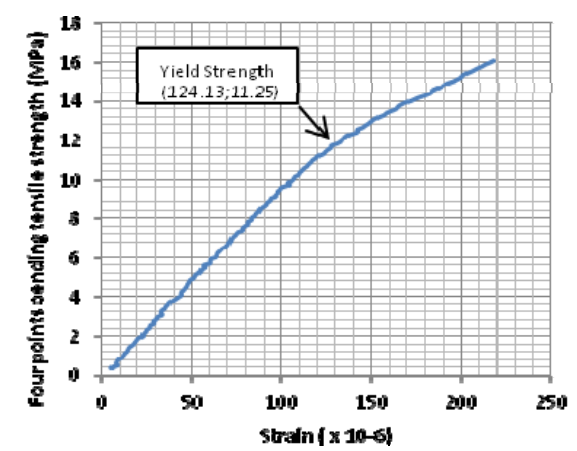

Fig. 6. Curve of stress versus strain deformation behavior of the black São Gabriel obtained in the four-point load test (thickness of 20 millimeters).

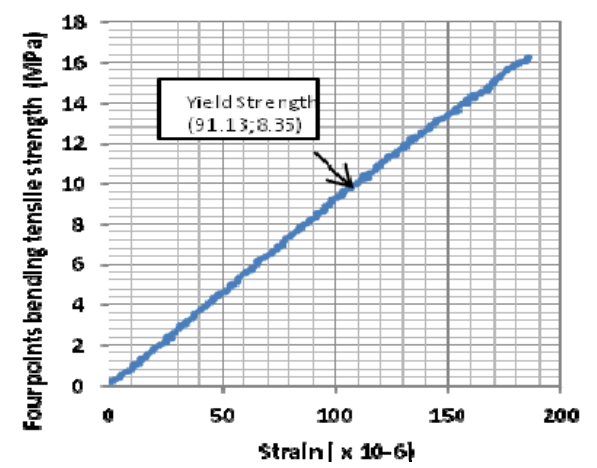

Fig. 7. Curve of stress versus strain deformation behavior of the black São Gabriel obtained in the four-point load test (thickness of 30 millimeters).

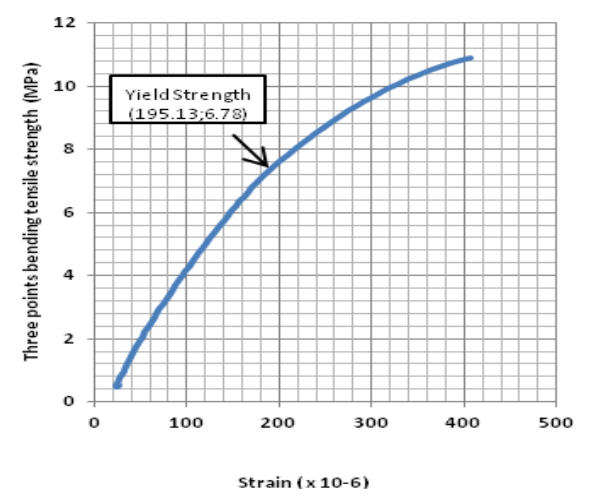

Fig. 8. Curve of stress versus strain deformation behavior of the black São Gabriel obtained in the three-point load test (thickness of 20 millimeters).

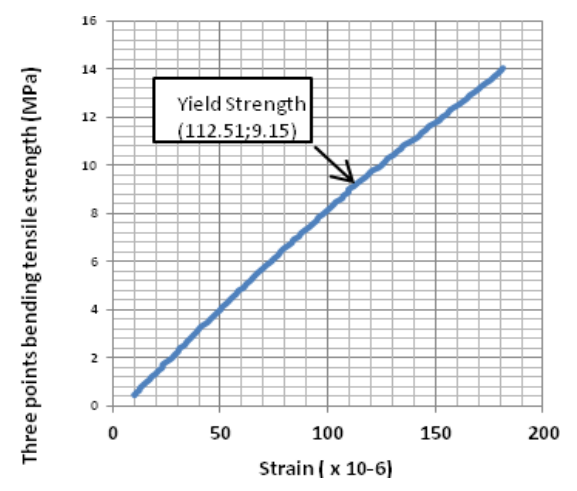

Fig. 9. Curve of stress versus strain deformation behavior of the black São Gabriel obtained in the three-point load test (thickness of 30 millimeters).
TABLE II: BENDING TENSILE TEST YounG'S MODULus RESUlTS

\begin{tabular}{ccc}
\hline Test & $20 \mathrm{~mm}$ & $30 \mathrm{~mm}$ \\
\hline 3 points load test & 92.26 & 92.48 \\
4 points load test & 98.65 & 87.66 \\
\hline
\end{tabular}

The results of the ultimate strength of compressive mode $(\sigma c)$, the respective Youns's modulus (E) and Poisson's ratio $(\mu)$ are presented Table III. The stress versus strain behavior curve is presented in Fig. 10.

TABLE III: UltimATE COMPRESSION STRENGTH, YOUNG MODULUS AND

\begin{tabular}{cccc}
\multicolumn{4}{c}{ POISSON's RATIO RESULTS } \\
\hline Test & $\begin{array}{c}\sigma_{f} \\
(\mathrm{MPa})\end{array}$ & $\begin{array}{c}\text { S.D. } \\
(\mathrm{MPa})\end{array}$ & C.V. \\
\hline$\sigma_{c}(\mathrm{MPa})$ & 101.79 & 7.56 & 0.074 \\
$E(\mathrm{GPa})$ & 79.06 & 2.22 & 0.028 \\
$\mu$ & 0.24 & 0.042 & 0.176
\end{tabular}

Legend: $\sigma f$ is the bending tensile results media, S.D. is the standard deviation and C.V. is the coefficient of variation.

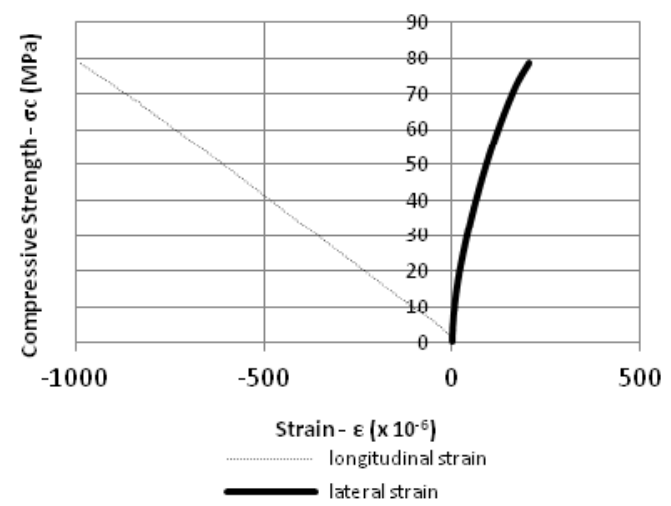

Fig. 10. Curve of stress versus strain deformation behavior of the black São Gabriel obtained in the three-point load test (thickness of 30 millimeters).

Our study presented five static methods for determining the Young's modulus. The Black São Gabriel results had an average of $90.00 \mathrm{GPa}$, standard deviation of $7.24 \mathrm{GPa}$ and coefficient of variation of $8.04 \%$. The coefficient of variation had lower results than $10 \%$, indicating a strong correlation between the values.

\section{CONCLUSIONS}

The methodology presented determines all necessary parameters - ultimate strength $(\sigma c)$, Young's modulus (E) and Poisson's coefficient $(\mu)$ - for the stone plates design in non-adherent floor covering systems. It also allows evaluating the stress versus strain deformation behavior of stones in the compression and bending modes.

For the Black São Gabriel any of the five Young's modulus (E) obtained can be used in the design of non-adherent covering systems.

\section{REFERENCES}

[1] Federation of Industries of São Paulo, Building Construction: Industrial Policies, DECONCIC/FIESP, São Paulo, 2008.

[2] Quality Stone, Editorial, EMC Editores Associados, São Paulo, 2011.

[3] Natural stone test Methods, Determination of Linear Thermal Expansion Coefficient, BS EN standard 14581 - 2004.

[4] Slabs of Natural Stones for External Paving. Requirements and Test Methods, BS EN standard 1341 - 2001.

[5] Natural Stone Products - Slabs for Floors and Stairs - Requirements, BS EN standard 12058- 2004. 
[6] Concrete paving flags - Requirements and Test Methods, BS EN 1339 2003.

[7] Test Method for Flexural Strength of Dimension Stone, ASTM C 880 2009.

[8] Test Method for Compressive Strength and Elastic Moduli of Intact Rock Core Specimens under Varying States of Stress and Temperatures, ASTM D 7012 - 2010.

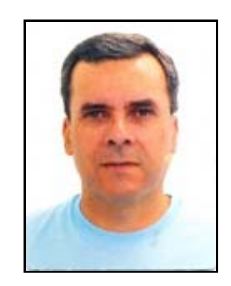

Rogério P. Ribeiro is a doctor in geotechnical engineering from University of São Paulo, he is a lecturer of engineering geology in Engineering School of São Carlos, University of São Paulo. His main subject of research is focused on characterization of rocks and sediments for using as construction materials. His professional experience is in mining exploration and dam projects.

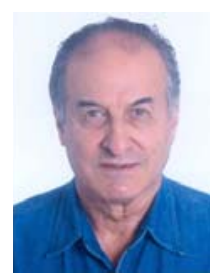

Antenor B. Paraguassú is a doctor at Geology, University of São Paulo in 1968. He is a full professor of engineering geology, Engineering School of São Carlos, University of São Paulo. His main subject of interest is focused on dimensional stones with emphasis in processing and slab affixing using adherent and non-adherent systems.

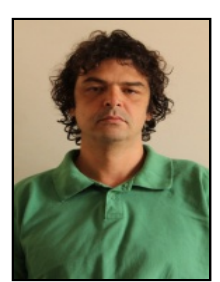

Sérgio T. F. Moreiras is a doctor in geotechnical engineering from University of São Paulo. He is a lecturer of geotechnical engineering at State University of Maringa, with professional experience in infrastructure design and construction. 